\section{Prevalence, Aetiology and Outcome of Status Epilepticus in Children with Convulsions at the Wesley Guild Hospital, Ilesa}

\author{
Olubosede $\mathrm{OA}^{1^{*}}$, Oseni SBA ${ }^{2}$, Aladekomo $\mathrm{TA}^{2}$, Adegoke $\mathrm{SA}^{2}, \mathrm{Kuti}^{\mathrm{B}}{ }^{2}$, Ogundare $\mathrm{OE}^{3}$, Bello EO ${ }^{1}, \mathrm{Jegede} \mathrm{CT}^{4}$ and Salau QO \\ ${ }^{1}$ State Hospital Akure, Ondo State, Nigeria \\ 2Obafemi Awolowo University Teaching Hospital, Ile-Ife, Nigeria \\ ${ }^{3}$ Ekiti State University Teaching Hospital, Ado Ekiti, Nigeria \\ ${ }^{4}$ Federal Medical Centre, Owo, Ondo State, Nigeria
}

*Corresponding author: Olubosede OA, Consultant Paediatrician, State Hospital Akure, Ondo State, Nigeria, Tel: 2347069647973 ; E-mail: oolubosede@yahoo.com

Received date: September 23, 2016; Accepted date: November 07, 2016; Published date: November 15, 2016

Copyright: (c) 2016 Olubosede OA, et al. This is an open-access article distributed under the terms of the Creative Commons Attribution License, which permits unrestricted use, distribution, and reproduction in any medium, provided the original author and source are credited.

\begin{abstract}
Status epilepticus (SE) in childhood is a life threatening condition with serious risk of neurological sequelae and constitutes a medical emergency. The aim of this study is to provide data on the prevalence, aetiology and outcome of status epilepticus in children at the Wesley Guild Hospital, llesa, South-West Nigeria. We prospectively studied all the 276 children who were admitted with convulsion over a period of seven months, out of which $39(14.1 \%)$ had status epilepticus. The cause of status epilepticus in $82.1 \%$ of the patients was cerebral malaria; other causes were febrile convulsion, meningitis, seizure disorders and head injury. The mortality and morbidity (neurologic sequelae at discharge) in this study were $23.1 \%$ and $33.3 \%$, respectively. Mortality and morbidity were significantly higher in children who had status epilepticus compared to those who convulsed but did not have status. $\left(x^{2}=33.773\right.$, $d f=1$, $p<0.001),\left(x^{2}=43.991, d f=1, p<0.001\right)$.
\end{abstract}

In conclusion, morbidity and mortality of SE is high and control of malaria will most likely reduce the prevalence and improve the outcome of SE in this environment.

Keywords: Status epilepticus; Prevalence; Outcome; Neurologic sequelae

\section{Introduction}

Status epilepticus is defined as a continuous convulsion lasting more than $30 \mathrm{~min}$ or the occurrence of serial convulsions between which there is no return to consciousness for a period greater than $30 \mathrm{~min}$ [1-4]. Status epilepticus in childhood is a life threatening condition with serious risk of neurological sequelae and constitutes a medical emergency [2,4,5]. According to the Canadian Paediatric society the commonest cause of status epilepticus is prolonged febrile convulsion [6]. This may not be so in Africa where infectious conditions such as cerebral malaria and meningitis are relatively frequent causes of convulsion [7-9]. Exposure to falciparum malaria increases the risk of status epilepticus [10]. In fact, Newton and Kariuki concluded that malaria is the most cause of status epilepticus in malaria endemic areas [10]. Central nervous system (CNS) infections may predominate in children with fever and cerebral malaria can be a common cause in malaria endemic area [11-13]. Other causes of status epilepticus include epilepsy, head trauma, intoxication, tumors, metabolic disorders, haemorrhage, drug withdrawal, hypoglycaemia and structural abnormality of the CNS $[10,14,15]$.

There is paucity of data on the prevalence of status epilepticus locally, but in the study by Idro et al. in Kenya, 98 (10.9 percent) of the children seen with convulsion had status epilepticus and falciparum malaria was the main illness in 56 (57.1 percent) of the patients [8]. Although it is believed that the prevalence of SE in Africa is high, published data on prevalence in the continent are few $[8,10]$. The hospital-based cohort study carried out in Kenya reported a minimum incidence of 35/100,000/year in children between the ages of 0-13 year [16]. This is referred to as the minimum incidence since a proportion of the children with SE will die before reaching the hospital, and others will be treated in private hospitals $[10,16]$. The incidence of convulsive status epilepticus in London, UK, has been reported as 18-20 per 100,000 per year in children less than 16 years old [17]. A hospitalbased study involving 22 states in the United States of America 4 reported a prevalence of 0.083 percent. The incidence of SE in SubSahara Africa is higher and this may be due to the presence of malaria and other CNS infections, and late presentation in the hospital for treatment when children have fever or are convulsing $[8,10,16]$.

There is little agreement between hospital protocols when treating status epilepticus in children [18]. In many African hospitals, antiepileptic drugs available for the treatment of SE are limited mainly to diazepam and phenobarbital, and supply is sometimes erratic $[10,19]$.

Convulsive status epilepticus is associated with significant mortality and morbidity [10,12,17,20,21]. Morbidity and mortality are highest with SE associated with CNS infections, which is the most important cause of SE [22]. Although, it is commonly agreed that outcome is primarily a function of underlying aetiology, there is still much controversy as to which other factors such as age, duration, treatment or CSE itself, modify the outcome $[12,21,23,24]$. Where there has been no acute or progressive central nervous system insult, morbidity and mortality are low $[4,5,17,20,25-27]$. Failure to diagnose and treat status epilepticus in a prompt and accurate manner has been shown to result in significant overall mortality and neurological morbidity $[17,23,28]$. The mortality in Sub-Saharan Africa is higher than in the resource-rich 
Citation: Olubosede OA, Oseni SBA, Aladekomo TA, Adegoke SA, Kuti BP, et al. (2017) Prevalence, Aetiology and Outcome of Status Epilepticus in Children with Convulsions at the Wesley Guild Hospital, llesa. J Pediatr Neurol Med 2: 116. doi:10.4172/2472-100X. 1000116

Page 2 of 5

countries. This may be due to the delay in presenting to hospital, poor management of SE in hospital and the underlying aetiology, lack of infrastructure or transport may further delay presentation to the hospital $[16,23,29]$. There are limited facilities and staff to manage patients in many hospitals in Africa. Status epilepticus was found to be independently associated with neurological deficit at discharge as well as with mortality in children with acute seizures [8] The morbidity and mortality associated with status epilepticus is much higher developing in developing and resource-poor countries than it is in developed countries $[10,12,16,17,21,29]$.

The prevalence of SE is high in Africa and the major cause is infection especially malaria and meningitis. The outcome of SE particularly in Africa could be improved through adequate malaria control, prevention of CNS infections especially meningitis, appropriate early management of seizures, education, development of appropriate guidelines, and provision of appropriate facilities and infrastructure $[8,10,16]$.

We assess the prevalence, aetiology and outcome of SE in children admitted with convulsion in a tertiary centre in Nigeria, a malaria endemic area.

\section{Subject and Methods}

This prospective, cross-sectional study was conducted at the Children Emergency Room of the Wesley Guild Hospital (WGH) Ilesa, of Obafemi Awolowo Teaching Hospital Complex (OAUTHC), Ile-Ife. Permission for the study was granted by the Ethics and Research Committee of the hospital. For each child, verbal and written informed consent was also obtained from the parent (s) or the accompanying relative (s). A study proforma designed to document pertinent historical information and findings on physical examination was completed for each patient. All the children with convulsions were reviewed. Only those who fulfilled the criteria for status epilepticus and gave informed consent were recruited.

The duration of convulsion, number of episodes of convulsion, duration of unconsciousness, previous convulsion with or without fever and use of antiepileptic drugs were noted. History of fever and its duration, eye discharge, body rash, passage of loose stool were also noted. Investigations carried out on the children with convulsions included packed cell volume, blood film for malaria parasite, blood chemistry, random blood sugar, lumbar tap for cerebrospinal fluid analysis and others like skull radiograph as indicated [1]. Lumbar tap was done in all the children according to the departmental protocol.

The main objectives of treatment of the children were support of vital functions following $\mathrm{ABC}$ principles of resuscitation, termination of seizures and identification and treatment of causal or precipitating factors [24]. Associated problems and complications were also identified and treated. Convulsions were treated acutely with deep intramuscular paraldehyde or intravenous diazepam. A convulsing child is given intravenous (IV) diazepam $0.2 \mathrm{mg} / \mathrm{kg}$ at a rate not greater than $2 \mathrm{mg} / \mathrm{min}$ or deep intramuscular (IM) paraldehyde at 1 $\mathrm{ml} / \mathrm{kg}$ to a maximum of $5 \mathrm{ml}$, whichever was immediately available. If the seizures were continuing at $10 \mathrm{~min}$, intravenous (IV) diazepam or deep intramuscular (IM) paraldehyde, whichever was not given initially was given. Seizures continuing at $20 \mathrm{~min}$, phenobarbitone 15 $\mathrm{mg} / \mathrm{kg}$ slow IV loading dose then at $2.5 \mathrm{mg} / \mathrm{kg} 12 \mathrm{~h}$ and IM paraldehyde. If seizures were continuing at $30 \mathrm{~min}$, diazepam infusion in normal saline or $5 \%$ dextrose water at $0.2 \mathrm{mg} / \mathrm{kg} / \mathrm{h}$. Bearing in mind the risk of respiratory depression, resuscitation trolley was made available on hand while the anaesthetist was invited. If seizures duration is more than $40 \mathrm{~min}$, induce general anaesthesia using thiopentone $4 \mathrm{mg} / \mathrm{kg}$ and transfer to intensive care unit. Patient was closely monitored by repeated physical and neurological examinations.

The outcome in this study included death, discharged with or without neurologic deficits and discharged against medical advice. Examinations for neurologic deficits were done at discharge. Data were analysed using the SPSS for Window software version 16 package. Means and standard deviations (SD) were computed and where necessary, comparisons of means were done using the Student's " $t$ " test, while proportions were compared using the Chi square $\left(\chi^{2}\right)$ test with Fishers exact probability test used as appropriate. Values of $\mathrm{p}<0.05$ were accepted as statistically significant.

\section{Results}

During the period of the study, 880 children were admitted into the Children Emergency Ward out of which 276 had convulsions. Of the 276 with convulsions, 39 (14.1\%) had status epilepticus consisting of $22(56.4 \%)$ boys and 17 (43.6\%) girls. Those with status epilepticus were $4.4 \%$ of the total admissions during the study period. The age range of the children with status epilepticus is 4 to 96 months 18.0 (19.45), mean (SD) and 20 (74.4\%) of them were less than three years. Of these 39 children with SE, 35 (89.7\%) had series of convulsions with failure to regain consciousness for a period longer than $30 \mathrm{~min}$ inbetween convulsion, three $(7.7 \%)$ had single convulsion lasting for more than $30 \mathrm{~min}$ and one (2.6\%) patient who had two episodes of convulsions; in which the second episode lasted for more than $30 \mathrm{~min}$ though he regained consciousness in-between the episodes. The diagnosis in the children with SE is as shown in Table 1. All the 3 children with the diagnosis of febrile convulsions were found to have malaria.

\begin{tabular}{|c|c|}
\hline Diagnosis & No. of patients (\%) \\
\hline Cerebral malaria & $30(76.9)$ \\
\hline Febrile convulsion & $3(7.7)$ \\
\hline Meningitis & $2(5.1)$ \\
\hline Seizure disorder & $2(5.1)$ \\
\hline Afebrile seizure & $1(2.6)$ \\
\hline Head injury & $1(2.6)$ \\
\hline
\end{tabular}


Citation: Olubosede OA, Oseni SBA, Aladekomo TA, Adegoke SA, Kuti BP, et al. (2017) Prevalence, Aetiology and Outcome of Status Epilepticus in Children with Convulsions at the Wesley Guild Hospital, llesa. J Pediatr Neurol Med 2: 116. doi:10.4172/2472-100X. 1000116

Page 3 of 5

\section{Total}

$39(100)$

Table 1: The diagnosis in children with status epilepticus.

\section{The outcome in the children with status epilepticus}

Four of the 39 patients with SE had hypoglycaemia out of which 3 (75\%) died. Seventeen $(43.6 \%)$ of the 39 children had anaemia that required blood transfusion. Out of the 17 patients requiring blood transfusion, six (35.3\%) died, six (35.3\%) were discharged with neurologic deficits and $5(29.4 \%)$ were discharged home without neurologic deficits.

Of the 39 children with status epilepticus, one (2.6\%) discharge against medical advice, nine (23.1\%) died, 13 (33.3\%) developed neurologic sequelae while the remaining $16(41.0 \%)$ were discharged home without obvious neurologic sequelae. Compared with three (1.3\%) of the remaining 234 children who had convulsion but without status epilepticus that died, a significantly higher proportion of patients with status epilepticus died $\left(\chi^{2}=33.773, \mathrm{df}=1, \mathrm{p}<0.001\right)$. Also, in terms of development of neurologic deficit; 13 (44.8\%) of the 29 survivors with status epilepticus and 13 (5.6\%) of the remaining 231 children without status epilepticus had neurologic deficit. This difference was also significant statistically $\left(\chi^{2}=43.991, \mathrm{df}=1, \mathrm{p}<0.001\right)$. None of the children in this study required the induction of general anaesthesia to control the convulsions. None was managed in the intensive care unit because of its non-availability.

The diagnoses in the children that had neurologic deficits were cerebral malaria and meningitis. Eleven $(84.6 \%)$ had cerebral malaria while the remaining two had meningitis. The neurologic deficits found were regression of the attained developmental milestones in six $(46.4 \%)$ of the children. Other deficits found were cortical blindness, deafness, spasticity and facial nerve palsy. All the nine children that died had cerebral malaria. The deaths occurred within four days of admission, out of which two-third occurred within $48 \mathrm{~h}$ of admission.

\section{Autopsy}

Autopsy was requested for the patients that died in the study, but none of the parents/caregivers gave consent. They all said that it was an exercise without any benefit to them since the child in question was already dead. Eight of them further said that autopsy was an additional loss as they were required to pay for the procedure, while two refused for religious reasons.

\section{Discussion}

Status epilepticus is a neurologic emergency which is associated with significant morbidity and mortality when it is not promptly and adequately managed $[10,12,17,23,28]$. Status epilepticus is believed to be common in Africa but published data is sparse. This prospective study of prevalence, aetiolgy and outcome of status epilepticus in children admitted into a tertiary hospital in South-Western Nigeria was embarked on for this reason. The majority of the children studied, 94.9\% were under-5years while $17.9 \%$ were infants and there were more males. This is similar to the findings from earlier works $[29,30]$. The prevalence of status epilepticus among the 880 children ward admission in this study is $4.4 \%$. This is comparable to the $2.0 \%$ reported by Idro et al. in Kenya but higher than the $1.3 \%$ obtained another study in Uyo, Nigeria $[8,30]$. The lower value in Uyo study is probably due to data loss as it was a retrospective study. A prospective cohort study in Kenya reported an incidence of 35/100,000 [16]. The prevalence of status epilepticus in London is 18-20/100,000/year a rate similar to that in other developing countries [17,24]. Another paediatric inpatients data-based study from the US reported a prevalence of $0.08 \%$ [31]. The prevalence of status epilepticus in subSaharan is higher than that of other continents such as Europe and America. The larger burden is thought to be caused by an increase in the incidence of risk factors such as perinatal insults and parasitic disease [16,32]. The incidence of 35/100,000 reported from Kenya may be an underestimation since a proportion of these children will die before reaching the hospital and others would have been treated in private clinics $[8,16]$.

The commonest aetiology of status epilepticus in this present study is malaria. Complicated malaria was the cause of status epilepticus in $84.6 \%$ of the 39 children with status epilepticus. These complications were cerebral malaria and febrile convulsions. This high percentage contributed by malaria in the present study is in agreement with the reports of several other studies where $53 \%, 57.1 \%, 70.3 \%, 92 \%$ of status epilepticus has been attributed to malaria $[8,16,30,33]$. The pathologic hallmark of falciparum malaria is the sequestration of parasitized red blood cells in the deep microvasculature of the deep organs particularly the brain leading to local ischaemia and hypoxia [10]. Other aetiologies of status epilepticus found in the present study, meningitis, seizure disorder, afebrile seizure and head injury, have also been reported by other authors [30]. In sub-Saharan Africa, Nigeria inclusive, infections especially malaria and meningitis remain the leading causes of status epilepticus in the present study, $89.7 \%$ of status epilepticus were attributed to infections. The outcome in children with $\mathrm{SE}$ is close related to the aetiology of seizures and duration of convulsions [12,20,21,23,25]. Efforts to reduce the prevalence of malaria will therefore translate into reduction in the prevalence of status epilepticus and its attendants problems.

The mortality rate among the children with status epilepticus in the present study is $23.1 \%$. This is similar to the mortality rate of $19.2 \%$ reported from another study in Nigeria 30, 15\% reported in Kenya and the $30.0 \%$ reported from India [8]. A mortality rate of $13.0 \%$ was reported from another resource-poor country of Honduras while a mortality rate of $9.3 \%$ was reported in Iran $[23,34]$. The mortality rates reported from the developed countries ranging from $0-3 \%$ is much lower than that obtained in this study [21]. The outcome of status epilepticus is still poor in Nigeria and in sub-Saharan Africa due to several factors $[17,29,31,35,36]$. The higher mortality rates in these resource poor countries may be attributed to delays in accessing treatment and lack of skills and facilities such as intensive care units, infusion pumps and ventilators, unorthodox cultural practices before presentation in the hospitals and poor infrastructure, prevalence of parasitic diseases, non-availability of appropriate and effective drugs $[10,16,19,23,29,30,37]$. Another contributor to the poor outcome in Africa may be the prolonged duration of anoxia from prolonged seizure activity which may be associated with status epilepticus and may lead to irreversible cerebral injury. [17,24]. The need for early presentation of the children with convulsion to the hospital for prompt diagnosis and treatment to reduce the duration of convulsion cannot 
Citation: Olubosede OA, Oseni SBA, Aladekomo TA, Adegoke SA, Kuti BP, et al. (2017) Prevalence, Aetiology and Outcome of Status Epilepticus in Children with Convulsions at the Wesley Guild Hospital, Ilesa. J Pediatr Neurol Med 2: 116. doi:10.4172/2472-100X. 1000116

Page 4 of 5

be over-emphasized especially when convulsion at home does not spontaneously stop within few min $[8,16,30]$. The presence of hypoglycaemia is found to be significantly associated with the risk of death in this study. This is in agreement with the finding by Idro et al. [8] in Kenya and Loddenkemper et al. in US [31]. A third, 33.3\% of the children in this study developed neurologic deficits [31]. This high morbidity rate is similar to $33 \%$ found in Korea children and $56.3 \%$ in India [38]. Other studies have reported lower rates of $6-15 \%$ [20]. Recent reports from the developed countries is that the outcome of status epilepticus is improving with early recognition, adequate monitoring and appropriate care, unfortunately, same cannot be said of the developing countries where the health system is still faced with a lot of challenges $[16,21,23,29,30,39,40]$. Status epilepticus has been found to be significantly associated with risk of developing neurological sequelae and death. Mortality is also closely related to the cause of the status epilepticus $[12,20,21,25,31]$. The neurologic deficits found in this study were regression of the attained developmental milestones in six (46.4\%) of the children. Other deficits found were cortical blindness, deafness, spasticity and facial nerve palsy. Other authors have also reported similar deficits [8.]

\section{Conclusion}

In conclusion, status epilepticus is common and potentially dangerous disorder in children with convulsion. The main aetiology in Nigeria is complicated malaria because of endemicity of malaria. The associated mortality and morbidity is also unacceptably high due to several reasons already highlighted. Prevention of malaria and its complication of cerebral malaria will reduce the burden of status epilepticus in Nigeria. This study may be limited by the fact that the diagnosis of cerebral malaria was only clinical.

There should also be continuous health education of the populace on the importance of early presentation in the hospital when children are ill or convulsing for appropriate management. There is also need to local guidelines on management of status epilepticus and provision of appropriate facilities in health institutions.

\section{Acknowledgement}

We are grateful to the resident doctors and the nursing staff of the Children Emergency Ward of the Wesley Guild Hospital Ilesa for their support in the management of the patients. We also thank the patients who participated in this study and their relations for their cooperation.

\section{Competing Interest}

None

\section{Funding}

This research did not receive any specific grant from funding agencies in the public, commercial, or not-for-profit sectors.

\section{References}

1. Commission on epidemiology and prognosis, International league against epilepsy (1993) Guidelines for epidemiological studies on epilepsy. Epilepsia 34: 592-596.

2. (1996) Stopping status epilepticus. Drug Ther Bull 34: 73-75.

3. Tasker RC (1998) Emergency treatment of acute seizures and status epilepticus. Arch Dis Child 79: 78-83.
4. Scott RC, Surtees RA, Neville BG (1998) Status epilepticus: Pathophysiology, epidemiology and outcomes. Arch Dis Child 79: 73-77.

5. Smith RA, Martland T, Lowry MF (1996) Children with seizures presenting to accident and emergency. J Accid Emerg Med 13: 54-58.

6. Canadian Paediatrics Society (CPS) (1996) Management of the paediatric patient with generalized convulsive status epilepticus in the emergency department. Paediatrics and Child Health 1:151-155.

7. Uzodike VO (1976) Paediatric emergencies in general practice. Nig J Paediatr 3: 39.

8. Idro R, Giver S, Kahindi M, Gatakaa H, Kazungu T, et al. (2008) The incidences, aetiology and outcome of acute seizure in children admitted to a rural Kenyan district hospital. BMC Pediatric 85.

9. Wammanda RD, Ali FU (2004) Conditions associated with the risk of death with 24 h of admission. Ann Afr Med 3: 134-137

10. Newton CR, Kariuki SM (2013) Status epilepticus in sub-Saharan Africa: New findings. Epilepsia 54 Suppl 6: 50-53.

11. Chin RF, Neville BG, Scott RC (2005) Meningitis is a common cause of convulsive status epilepticus with fever. Arch Dis Child 90: 66-69.

12. Lin KL, Lin JJ, Hsia SH, Wu CT, Wang HS (2009) Analysis of convulsive status epilepticus in children of Taiwan. Pediatr Neurol 41: 413-418.

13. Crawley J, Smith S, Kirkham F, Muthinji P, Waruiru C, et al. (1996) Seizures and status epilepticus in childhood cerebral malaria. QJM 89: 591-597.

14. DeLorenzo RJ, Kirmani B, Deshpande LS, Jakkampudi V, Towne AR, et al. (2009) Comparisons of the mortality and clinical presentations of status epilepticus in private practice community and university settings in Richmond, Virginia. Seizures 18: 405-411.

15. Sanya EO (2004) Status epilepticus-A review article. Niger J Med 13: 89-97.

16. Sadarangani M, Seaton C, Scott JA, Ogutu B, Edwards T, et al. (2008) Incidence and outcome of convulsive status epilepticus in Kenyan children: A cohort study. Lancet Neurol 7: 145-150.

17. Chin RF, Neville BG, Peckham C, Bedford H, Wade A, et al. (2006) NLSTEPSS collaborative group. Incidence, cause and short-term outcome of convulsive status epilepticus in childhood: Prospective populationbased study. Lancet 368: 222-229.

18. Martland T, Baxter P, Rittey C (1998) Is there an agreed treatment for children in status epilepticus? Dev Med Child Neurol 40: 286-287.

19. Wilmshurst JM, van der Walt JS, Ackermann S, Karlsson MO, Blockman M (2010) Rescue therapy with high-dose oral phenobarbitone loading for refractory status epilepticus. J Paediatr Child Health 46: 17-22.

20. Visudtibhan A, Limhirun J, Chiemchanya S, Visudhiphan P (2006) Convulsive status epilepticus in Thai children at Ramathibodi Hospital. J Med Assoc Thai 89: 803-808.

21. Barzegar M, Shiva S, Rahbari-Banaeian G (2014) Etiology and short-term outcome of children with convulsive status epilepticus admitted to Tabriz children Hospital, Iran. J Anal Res Clin Med 2: 112-117.

22. Hubert P1, Parain D, Vallée L (2009) Management of convulsive status epilepticus in infants and children. Rev Neurol (Paris) 165: 390-397.

23. Molinero MR, Holden KR, Rodriguez LC, Collins JS, Samra JA, et al. (2009) Pediatric convulsive status epilepticus in Honduras, Central America. Epilepsia 50: 2314-2319.

24. Raspall-Chaure M, Scott RC (2007) Convulsive status epilepticus in children. Ann Indian Acad Neurol 10: 7-18

25. Maytal J, Shinnar S, Moshé SL, Alvarez LA (1989) Low morbidity and mortality of status epilepticus in children. Pediatrics 83: 323-331.

26. Hauser WA (1983) Status epilepticus: Frequency, etiology and neurological sequelae. Adv Neurol 34: 3-14.

27. Drislane FW (2006) Who's afraid of status epilepticus? Epilepsia 47: 7-9.

28. Metsäranta P, Koivikko M, Peltola J, Eriksson K (2004) Outcome after prolonged convulsive seizures in 186 children: Low morbidity, no mortality. Dev Med Child Neurol 46: 4-8. 
Citation: Olubosede OA, Oseni SBA, Aladekomo TA, Adegoke SA, Kuti BP, et al. (2017) Prevalence, Aetiology and Outcome of Status Epilepticus in Children with Convulsions at the Wesley Guild Hospital, Ilesa. J Pediatr Neurol Med 2: 116. doi:10.4172/2472-100X. 1000116

Page 5 of 5

29. Wilmshurst JM, Badoe E, Wammanda RD, Mallewa M, Kakooza-Mwesige A, et al. (2011) Child neurology services in Africa. J Child Neurol 26: 1555-1563.

30. Akpan MU, Nyong EE, Abasiubong (2011) Pre-hospital treatment and outcome of status epilepticus in children in Nigeria. Case Study Case Rep 1: 82-91.

31. Loddenkemper T, Syed TU, Ramgopal S, Gulati D, Thanaviratananich S et al. (2012) Risk factors associated with death in in-hospital pediatric convulsive status epilepticus. PLoS One 7: e47474.

32. Newton CR, Garcia HH (2012) Epilepsy in poor regions of the world. Lancet 380: 1193-1201.

33. Kariuki SM, Ikumi M, Ojal J, Sadarangani M, Idro R, et al. (2011) Acute seizures attributable to falciparum malaria in an endemic area on the Kenyan coast. Brain 134: 1519-1528.

34. Gulati S, Kalra V, Sridhar MR (2005) Status epilepticus in Indian children in a tertiary care center. Indian J Pediatr 72: 105-108.
35. Betjemann JP, Josephson SA, Lowenstein DH, Burke JF (2015) Trends in status epilepticus- related hospitalizations and mortality: Redefined in US practice over time. JAMA Neurol 72: 650-655.

36. Hussain N, Appleton R, Thorburn K (2007) Aetiology, course and outcome of children admitted to paediatric intensive care with convulsive status epilepticus: A retrospective 5 year review. Seizure 16: 305-312.

37. Newton CR (2009) Status epilepticus in resource-poor countries. Epilepsia 50 Suppl 12: 54-55.

38. Kang DC, Lee YM, Lee J, Kim HD, Coe C (2005) Prognostic factors of status epilepticus in children. Yonsei Med J 46: 27-33.

39. Mikati MA (2007) Status epilepticus. In: Behrman RE, Kliegman RM, Jenson HB, Stanton BF. Nelson textbook of Paediatrics 18th edition. Philadelphia, WB Saunders 2301-2303.

40. Gross-Tsur V, Shinnar S (1993) Convulsive status epilepticus in children. Epilepsia 34 Suppl 1: S12-20. 